\title{
Kooperation ÖOG mit vielgesundheit.at
}

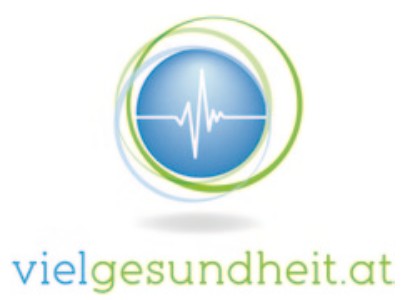

Die Gesellschaft berichtet:

Im Zuge der Awareness-Kampagne ,Augenblick - Österreich schaut zum Augenarzt' realisiert die Ophtalmologische Gesellschaft in Kooperation mit der österreichischen MedizinMediathek vielgesundheit.at zahlreiche Aufklärungsfilme in HD Qualität rund um das Thema Augengesundheit. Von der torischen Kontaktlinse über AMD-Prävention bis hin zur Lasertherapie werden sämtliche Kernbereiche der Augenheilkunde abgedeckt.

Ziel ist es, die Bedeutung der Augenheilkunde sowie der österreichischen Augenärzte hervorzuheben und die Wertigkeit derselben zu steigern.

Das Medium Film eignet sich für Patientenaufklärung besonders gut, weil bewegte Bilder leicht erfassbar sind, direkt ansprechen und Vertrauen schaffen. Die Zuseher bekommen so einen Einblick in die Arbeitsbereiche österreichischer Augenärzte, werden über neue Therapiemethoden und über die Bedeutung von Vorsorgeuntersuchungen informiert. Letztlich werden Ängste genommen und Mut gemacht, die angebotenen Leistungen in Anspruch zu nehmen.

Die Gesellschaft stellt die Filme ihren Mitgliedern als Service zur Patientenaufklärung zur Verfügung und nutzt diese auch auf der eigenen Webseite oder auf Kongressen und Tagungen als bewusstseinsschaffendes Medium.

Die Beiträge werden darüber hinaus 12 Monate auf der Webseite vielgesundheit.at gezeigt und zusätzlich über deren Kooperationspartner wie SpringerMedizin.at beworben.

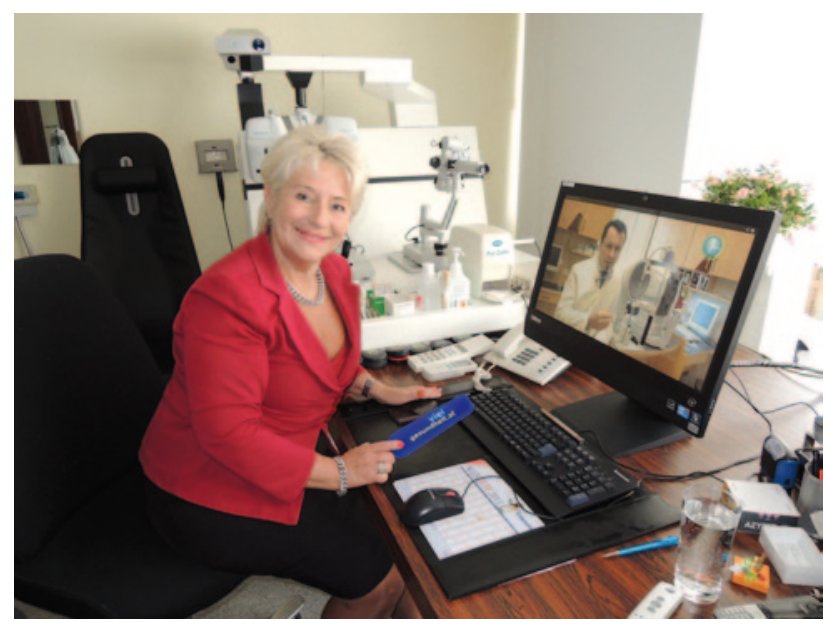

Präsidentin Dr. Helga Azem über die Zusammenarbeit mit vielgesundheit.at: „Es freut mich sehr, mit der MedizinMediathek vielgesundheit.at einen Kooperationspartner gefunden zu haben, der uns mit dem adäquaten Medium Film dabei unterstützt, medizinische Vorsorge und Therapiemöglichkeiten im Bereich der Ophtalmologie zu thematisieren und Ängste und Hürden der Patienten im Umgang mit dem österreichischen Gesundheitssystem abzubauen." 